\title{
Potential roles of nitric oxide in COVID-19: A perspective
}

\author{
Achala de Mel* \\ Centre for Translational Medicine and Therapeutics William Harvey Research Institute, Queen Mary University of London, NuTissu Ltd, UK
}

\begin{abstract}
Coronavirus disease 2019 (COVID-19) is a respiratory tract infection caused by a beta-coronavirus closely linked to the SARS coronavirus. COVID-19 patients present with hypoxemia linked to acute respiratory distress syndrome (ARDS). Reversing the hypoxemia prevalent in COVID-19 requires advanced mechanisms that facilitate the transportation of oxygen from alveoli to blood, as increased supplemental oxygen does not always lead to optimal oxygen saturation. Clinical and experimental evidence suggest a significant role for inhaled Nitric Oxide (NO) as a selective vasodilator, which has shown to restore oxygenation by helping to normalise shunts and ventilation/perfusion mismatch. NO has demonstrated the ability to suppress the replication of a respiratory corona virus, which is unique for NO among other vasodilators. These suggest a potentially significant role for NO in the clinical management of COVID-19, warranting urgent investigations into optimal methods of harnessing its potential in restoring pulmonary physiology.
\end{abstract}

\section{Introduction}

The pathophysiological conditions and clinical evidence associated with COVID-19 are rapidly being established, supporting the development of therapeutic solutions [1,2]. COVID-19 patients present with respiratory characteristics of acute respiratory distress syndrome (ARDS), which in accordance with The Berlin definition includes; new or worsening respiratory symptoms within one week of symptom onset; bilateral opacities on chest imaging not fully explained by effusions, atelectasis or nodules; respiratory failure from lung edema not fully explained by cardiac failure or fluid overload; and finally oxygenation impairment [3]. However, the ARDS presented with COVID-19 is recognised to be atypical as an alarmingly majority do not experience breathlessness and have relatively good lung compliance, whilst presenting with hypoxia [4-6]. Supplemental oxygen can partially improve oxygen saturation. However, hypoxaemia due to shunt does not respond well to supplemental oxygen [7]. High levels of supplemental oxygen can be toxic but can be prevented by titrating [8]. Invasive mechanical ventilation, which is considered when addressing the most severe cases continues to be associated with a higher incidence of adverse outcomes [9]. Therefore, there is currently an incentive to explore alternative methods of optimal management of patients in addition to widely practiced prone positioning [10]. Methods of reducing pulmonary resistance and resolving oxygenation with noninvasive therapy are of interest [11].

Hypoxia is known to cause vasodilation in systemic arteries whilst causing vasoconstriction in pulmonary arterioles. Nitric Oxide (NO) has a major role in regulating hypoxia and in healthy conditions it was found that $\mathrm{NO}$ can mediate adaptive mechanisms including modulation of vasodilation. Hypoxia regulation in extreme conditions such as high altitudes has shown a strong link to NO, with large populationbased studies demonstrating NO upregulation as a physiological response [12]. Exhaled NO measurements associated with a range of respiratory disease conditions demonstrate specific variations in $\mathrm{NO}$ downregulation that correspond to an identifiable role in NO [13].

$\mathrm{NO}$ is a gaseous molecule and is primarily known for its role in regulating vascular compliance via cGMP pathway [14]. It is synthesised by the endothelial cells lining both healthy blood vessels, and platelets. NO prevents thrombotic complications by inhibiting blood coagulation and regulates blood flow. It is also synthesised in epithelial cells and is known for its potent antimicrobial properties as well as its ability to suppress the rate of viral replication $[15,16]$. NO synthesis is known to be impaired with co-morbidities that include metabolic syndrome and diabetes, thus it is arguable that impaired NO synthesis could be co-related to COVID-19 patient groups that are most severely affected $[17,18]$.

The entry point of the coronavirus has been recognised to be Angiotensin Converting Enzyme 2 (ACE2) receptors, which are expressed in endothelial and epithelial cells [19]. ACE2 pathway is known to modulate a cascade of events including vascular compliance and vasodilation [20]. ACE2 has a direct effect in upregulation of Nitric Oxide Synthase demonstrated in ACE2 knockout mice with resulting vascular dysfunction and NO imbalance [21]. It would be beneficial to investigate whether potential therapeutic options to address COVID19, could be linked to this ACE2 -NO pathway.

This article presents the perspective that inhaled NO should be considered within the protocols in managing COVID-19, with the view that disruption to $\mathrm{NO}$ and related pathways may be leading complications related to COVID19. It is timely to evaluate the validity of this hypothesis and the results could be key, not only in managing COVID19, but also for the management of related hypoxic respiratory conditions.

\section{Nitric oxide improves oxygenation}

Inhaled NO with a half- life of around 3-5s diffuses from alveoli to vascular smooth muscle cells. These cells are adjacent $(\sim 1 \mu \mathrm{m})$ to the

${ }^{\star}$ Correspondence to: Achala de Mel, Centre for Translational Medicine and Therapeutics William Harvey Research Institute, Queen Mary University of London, NuTissu Ltd, UK, E-mail: demelach@gmail.com

Key words: COVID-19, infection, clinical management, nitric oxide, respiration

Received: May 05, 2020; Accepted: May 11, 2020; Published: July 15, 2020 
alveoli and causes selective pulmonary vasodilatation. This imparts an overall effect in pulmonary gas exchange, by increasing blood flow to well ventilated areas in the lung whilst simultaneously reducing the flow to areas of shunts $[22,23]$. NO has a high affinity to haemoglobin and gets deactivated upon binding to form methaemoglobin. In doing so it limits vasodilatory effects to ventilated areas of the lung [24]. Inhaled $\mathrm{NO}$ in the presence of superoxide is also converted into nitrogen dioxide, peroxy-nitrite and nitro-tyrosine. It should therefore be monitored and regulated to facilitate the positive effects of inhaled NO in reversing hypoxaemia. This could be done by controlling the dose and rate of inhaled NO introduction [14]. Pharmacological properties of inhaled nitric oxide can be linked to toxicological effects and should be considered when administering as therapeutic agent $[25,26]$.

Haemoglobin within red blood cells that successfully take up oxygen from alveoli need to carry $\mathrm{NO}$ in order to facilitate oxygen delivery to relevant tissues. NO through protein S-nitrosylation and formation of S-nitrosothiol has shown a significant role in regulating ventilation during hypoxia [27]. Conditions such as diabetes and sickle cell disease, which affect allosteric properties of haemoglobin tetramer, are impaired in the ability to carry $\mathrm{NO}$ and therefore oxygen delivery to tissues becomes impaired [28]. It would be interesting to investigate if hypoxaemia in COVID-19 is related to such impairments in haemoglobin, and if there are related changes to the NO carrying capacity.

Independent of COVID-19, ARDS was recognised in need of suitable strategies in its clinical management with a reported relatively high rate of admissions in Intensive Care Units (ICU) and a high rate of mortality. Disease conditions that injure lungs such as infection or pneumonia can cause ARDS. ARDS, Chronic Obstructive Pulmonary Disorder (COPD) and pulmonary embolism are major conditions that result in arterial hypoxemia. Low ventilation-perfusion (V/Q) and shunt are recognised to be most common causes of clinical hypoxemia and shunt most common in ARDS. There are numerous studies that have investigated the application of NO in ARDS as well as its application in managing critically ill patients in ICU [29-35]. Whilst there is no strong evidence to support a role for $\mathrm{NO}$ in directly reducing mortality, inhaled NO has very strong experimental and clinical evidence with improved oxygenation, at least for $72 \mathrm{hr}$ [35]. This could be a mortality determining factor in a resource limited COVID-19 situation and therefore inhaled NO could certainly be considered as a short-term rescue therapy to link with further management strategies [36-38]. Patients with greater baseline intrapulmonary shunt have demonstrated the most significant improvement in oxygenation and low dosed, (1040ppm) pulsed inhaled NO seem to be most effective [22,33-34]. Inhaled NO therefore should be considered prior to invasive ventilation and other treatment strategies such as extracorporeal membrane oxygenation for COVID-19 patients.

The effects of inhaled NO in COPD patients where hypoxemia is caused by low V/Q show a variable response within subgroups, within which the less consistent results are explained as a con-sequence of $\mathrm{NO}$ as a vasodilator reaching low V/Q regions. This in turn leads to greater arterial de-saturation. Unlike COPD, ARDS patients as well as those with acute severe pneumonia, have consistently and dramatically responded with a reduction in shunting and improved oxygenation [23]. Careful examination of systematic reviews that conclude an overall non-significant role for inhaled NO seem to base their conclusion with large variations in sub-groups. The authors themselves suggest caution to act on their conclusions and suggest further investigations would be beneficial. It is notable that even these systematic reviews have consistently highlighted a positive role of NO in oxygenation.

\section{Blood clot formation}

NO is well recognised for its role in inhibiting platelet aggregation and therefore its antithrombotic properties [39]. This could be yet another role for NO in managing COVID-19 patients who report increased D-dimer levels, and clot formation suggesting a pathological condition that could lead to thrombotic complications [40,41]. This is currently managed with prophylactic Heparin. Prostacyclin such as Epoprostenol is known as a potent anticoagulant and inhaled Epoprostenol is known to be effective as a vasodilator in severe hypoxemia [42]. Unlike NO, which has a selective, local pulmonary effect, prostacyclin could lead to a more systemic vasodilatory effect.

\section{Nitric oxide's antiviral role}

In addition to its vasodilatory and antithrombotic roles, NO has a key role in microbial infections particularly through its synthesis via inducible NO synthase (iNOS) [43]. A healthy airway epithelium can produce NO that acts as an antiviral agent in addition to providing a complex immune reactions in the pulmonary system [44-46]. Therefore, disease conditions that have impaired synthesis of NO could be salvaged with exogenous $\mathrm{NO}$ in the form of inhaled $\mathrm{NO}$ or NO releasing compounds, where innovative delivery mechanisms can be explored. SARS, which was caused by a Coronaviridae family virus had resulted in 774 deaths. NO has been shown to successfully inhibit its replication cycle by affecting its proteins and reduction in viral RNA [47-49]. Respiratory coronaviral infections have been recognised to induce epithelial cytolysis and NO releasing molecules, S-nitroso-Nacetylpenicillamine were able to preserve/restore rate of survival of SARS-Coronavirus infected cells [50,51].

\section{Overall perspective}

With an evident role in rapid re-oxygenation in ARDS, application of NO could be a mortality determining factor in a globally resource limited situation as COVID-19. Encouragingly, there are clinical trials underway to evaluate the effect of inhaled NO in managing COVID-19. These include "NO Gas Inhalation for Severe Acute Respiratory Syndrome in COVID-19 (NOSARSCOVID), NCT04290871", Nitric Oxide Inhalation Therapy for COVID-19 Infections in the ED (NO COV-ED), NCT04338828, High Dose Inhaled Nitric Oxide for COVID-19 (ICU Patients),NCT04383002, a study led by Novoteris and Mallinckrodt with a high-concentration form of NO named Thiolanox, Dose and rate of NO administration as well as degree of exposure to superoxide could significantly vary the responses in addition to variations in pathological conditions that underlie a given respiratory condition and therefore need to be carefully documented. There are opportunities to develop systems that detect and respond to such changes where the process can be automated possibly through integrating machine learning and artificial intelligent systems. NO therapy is associated with relatively high costs, and this has been a determining factor in integrating its applications in routine therapy. However, this reasoning would not be relevant to its applications in COVID19, considering the global spending related to the disease. The evidence of NO's ability to have a positive impact, based on the fundamental biochemical role of NO in hypoxemia, platelets, and potentially corona viral replication, calls for greater efforts to delineate NO's role and harness its undeniable positive role in managing the current global COVID-19 crisis. 


\section{Acknowledgments}

The author would like to thank all the clinicians who shared their insights on pathophysiology and clinical evidence on COVID19. The author is most grateful to Miss Sophie Milner for her most generous input with proofreading the article.

\section{References}

1. Zhu N (2020) A novel coronavirus from patients with pneumonia in China 2019. NEngl J Med 382: 727-733. [Crossref]

2. Andersen KG, Rambaut A, Lipkin W, Holmes EC, Garry RF (2020) The proximal origin of SARS-CoV-2. Nat Med 26: 450-452. [Crossref]

3. The ARDS Definition Task Force, Luigi C, Arthur SS (2012) Acute respiratory distress syndrome. The berlin definition. JAMA 307: 2526-2533. [Crossref]

4. Gattinoni L (2020) COVID-19 does not lead to a "typical" acute respiratory distress syndrome. Am J Respir Crit Care Med 201: 1299-1300. [Crossref]

5. Ottestad W, Søvik S (2020) COVID-19 patients with respiratory failure: what can we learn from aviation medicine? Br J Anaesth S0007: 30226-30229.

6. Luciano Gattinoni, Davide Chiumello, Pietro Caironi, Mattia Busana, Federica Romitti, et al. (2020) COVID-19 pneumonia: different respiratory treatments for different phenotypes? Intensive Care Med 14: 1-4.[Crossref]

7. Petersson J, Glenny RW (2014) Gas exchange and ventilation-perfusion relationships in the lung. Eur Respir J 44: 1023-1041.

8. Dobbe ASM, Stolmeijer R, Ter Maaten JC, Ligtenberg JJM (2018) Titration of oxygen therapy in critically ill emergency department patients: a feasibility study. BMC Emerg Med 18:17-20. [Crossref]

9. Kobayashi H, Uchino S, Takinami M, Uezono S (2017) The impact of ventilatorassociated events in critically ill subjects with prolonged mechanical ventilation. Respir Care 62: 1379-1386.

10. Kallet RH (2015) A comprehensive review of prone position in ARDS. Respir Care 60: 1660-1687. [Crossref]

11. Claar DD, Hyzy RC (2017) Refractory hypoxemia and acute respiratory distress syndrome adjunctive therapies: An open question?.Ann Am Thorac Soc 14: 1768-1769.

12. Levett DZ, Fernandez BO, Riley HL, Martin DS, Mitchell K, et al. (2011) The role of nitrogen oxides in human adaptation to hypoxia. Sci Rep 1:109.

13. Malinovschi A, Ludviksdottir D, Tufvesson E, Rolla G, Bjermer L, et al. (2015) Application of nitric oxide measurements in clinical conditions beyond asthma. Eur Clin Respir J 2: 28517. [Crossref]

14. Akter F, Coghlan G, de Mel A (2016) Nitric oxide in paediatric respiratory disorders: novel interventions to address associated vascular phenomena?. Ther Adv Cardiovasc Dis 10: 256-270. [Crossref]

15. Rimmelzwaan GF, Baars MM, de Lijster P, Fouchier RA, Osterhaus AD (1999) Inhibition of influenza virus replication by nitric oxide. J Virol 73: 8880-8883.

16. Karupiah G, Harris N (1995) Inhibition of viral replication by nitric oxide and its reversal by ferrous sulfate and tricarboxylic acid cycle metabolites. J Exp Med 181: 2171-2179. [Crossref]

17. Gao F, Zheng KI, Wang XB, Sun QF, Pan KH, Wang TY, et al. (2020) Obesity is a risk factor for greater COVID-19 severity. Diabetes Care 108: 154244. [Crossref]

18. Drucker DJ (2020) Coronavirus infections and type 2 diabetes-shared pathways with therapeutic implications. Endocr Rev 41: 1-10.

19. Yan R, Zhang Y, Li Y, Xia L, Guo Y, et al. (2020) Structural basis for the recognition of SARS-CoV-2 by full-length human ACE2. Science 367: 1444-1448

20. Patel KP, Schultz HD (2013) Angiotensin peptides and nitric oxide in cardiovascular disease. Antioxid Redox Signal 19: 1121-1132.

21. Rabelo LA, Todiras M, Nunes-Souza V, Qadri F, Szijártó IA, et al. (2016) Genetic deletion of ace 2 induces vascular dysfunction in $\mathrm{c} 57 \mathrm{bl} / 6$ mice: role of nitric oxide imbalance and oxidative stress. PLoS One 11: e0150255. [Crossref]

22. Hopkins SR, Johnson EC, Richardson RS, Wagner H, De Rosa M, et al. (1997) Effects of inhaled nitric oxide on gas exchange in lungs with shunt or poorly ventilated areas. Am J Respir Crit Care Med 156: 484-491. [Crossref]
23. Gómez FP, Amado VM, Roca J, Torres A, Nicolas JM, et al. (2013) Effect of nitric oxide inhalation on gas exchange in acute severe pneumonia. Respir Physiol Neurobiol 187: 157-63.

24. Stepuro TL, Zinchuk VV (2006) Nitric oxide effect on the hemoglobin-oxygen affinity. J Physiol Pharmacol 57: 29-38. [Crossref]

25. Weinberger B, Laskin DL, Heck DE, Laskin JD (2001) The toxicology of inhaled nitric oxide. Toxicol Sci 59: 5-16.

26. Radi R (2013) Peroxynitrite, a stealthy biological oxidant. J Biol Chem 288: 26464 26472. [Crossref]

27. Zhao Y, Wang X, Noviana M, Hou M (2018) Nitric oxide in red blood cell adaptation to hypoxia. Acta Biochim Biophys Sin (Shanghai) 50: 621-634. [Crossref]

28. McMahon TJ, Ahearn GS, Moya MP, Gow AJ, Huang YC, et al. (2005) A nitric oxide processing defect of red blood cells created by hypoxia: deficiency of S-nitrosohemoglobin in pulmonary hypertension. Proc Natl Acad Sci USA 102: 1480114806.

29. Levy SD, Alladina JW, Hibbert KA, Harris RS, Bajwa EK, et al. (2016) High-flow oxygen therapy and other inhaled therapies in intensive care units. Lancet 387 : 18671878. [Crossref]

30. Klinger JR (2002) Inhaled nitric oxide in ARDS. Crit Care Clin 18: 45-68.

31. Monsalve-Naharro JÁ, Domingo-Chiva E, García Castillo S, Cuesta-Montero P, Jiménez-Vizuete JM (2017) Inhaled nitric oxide in adult patients with acute respiratory distress syndrome. Farm Hosp 41: 292-312. [Crossref]

32. Haddad E, Lowson SM, Johns RA, Rich GF (2000) Use of inhaled nitric oxide perioperatively and in intensive care patients. Anesthesiology 92: 1821-1825. [Crossref]

33. Sahni R, Ameer X, Ohira-Kist K, Wung JT (2017) Non-invasive inhaled nitric oxide in the treatment of hypoxemic respiratory failure in term and preterm infants. $J$ Perinatol 37: 54-60.

34. Rossaint R, Lewandowski K, Zapol WM (2014) Our paper 20 years later: Inhaled nitric oxide for the acute respiratory distress syndrome--discovery, current understanding, and focussed targets of future applications. Intensive Care Med 40: 1649-1658. [Crossref]

35. Gebistorf F, Karam O, Wetterslev J, Afshari A (2016) Inhaled nitric oxide for acute respiratory distress syndrome (ARDS) in children and adults. Cochrane Database Syst Rev 6: CD002787. [Crossref]

36. Baxter FJ, Randall J, Miller JD, Higgins DA, et al. (2002) Rescue therapy with inhaled nitric oxide in critically ill patients with severe hypoxemic respiratory failure (Brief report). Can J Anaesth 49: 315-318.

37. Alessandri F, Pugliese F, Ranieri VM (2018) the role of rescue therapies in the treatment of severe ARDS. Respir Care 63: 92-101.

38. Busè M, Graziano F, Lunetta F, Sulliotti G, Duca V (2018) Inhaled nitric oxide as a rescue therapy in a preterm neonate with severe pulmonary hypertension: a case report. Ital J Pediatr 44: 50-55. [Crossref]

39. Everett W, Scurr DJ, Rammou A, Darbyshire A, Hamilton G, et al. (2016) A materia conferring hemocompatibility. Sci Rep 6: 26848.

40. Thachil J (2020) What do monitoring platelet counts in COVID-19 teach us? J Thromb Haemost. [Crossref]

41. Toolsie O, Gomceli U, Diaz-Fuentes G (2019) Inhaled nitric oxide as an adjunct to thrombolytic therapy in a atient with sub-massive pulmonary embolism and severe hypoxemia. Case Rep Crit Care 28: 5184702.

42. Buckley MS, Agarwal SK, Garcia-Orr R, Saggar R, MacLaren R (2020) Comparison of fixed-dose inhaled epoprostenol and inhaled nitric oxide for acute respiratory distress syndrome in critically Ill adults. J Intensive Care Med 5: 885066620906800. [Crossref]

43. Mannick JB (2006) Immunoregulatory and antimicrobial effects of nitrogen oxides. Proc Am Thorac Soc 3: 161-165. [Croosref]

44. Xu W, Zheng S, Dweik RA, Erzurum SC (2006) Role of epithelial nitric oxide in airway viral infection. Free Radic Biol Med 41: 19-28.

45. Bogdan C (2001) Nitric oxide and the immune response. Nat Immunol 2: 907-916.

46. Croen KD (1993) Evidence for antiviral effect of nitric oxide. Inhibition of herpes simplex virus type 1 replication. J Clin Invest 91: 2446-2452. [Crossref]

47. Akerstrom S, Mousavi-Jazi M, Klingstrom J, Leijon M, Lundkvist A (2005) Nitric oxide inhibits the replication cycle of severe acute respiratory syndrome coronavirus. J Virol 79: 1966-1969. 
48. Akerstrom S, Gunalan V, Keng CT, Tan YJ, Mirazimi A (2009) Dual effect of nitric oxide on SARS-CoV replication: viral RNA production and palmitoylation of the $\mathrm{S}$ protein are affected. Virology 395: 1-9.

49. Jung K, Gurnani A, Renukaradhya GJ, Saif LJ (2010) Nitric oxide is elicited and inhibits viral replication in pigs infected with porcine respiratory coronavirus but not porcine reproductive and respiratory syndrome virus. Vet Immunol Immunopathol 136 335-339. [Crossref]
50. Keyaerts E, Vijgen L, Chen L, Maes P, Hedenstierna G (2004) Inhibition of SARScoronavirus infection in vitro by S-nitroso-N-acetylpenicillamine, a nitric oxide donor compound. Int J Infect Dis 8: 223-226. [Crossref]

51. Chen L, Liu P, Gao H, Sun B, Chao D, et al. (2004) Inhalation of nitric oxide in the treatment of severe acute respiratory syndrome: a rescue trial in Beijing. Clin Infect Dis 39: 1531-1535.

Copyright: (C2020 de Mel A. This is an open-access article distributed under the terms of the Creative Commons Attribution License, which permits unrestricted use, distribution, and reproduction in any medium, provided the original author and source are credited. 